\title{
Incidence, dynamics, and prognostic value of acute kidney injury for death after cardiac surgery
}

\author{
Alain Dardashti, MD, ${ }^{\mathrm{a}}$ Per Ederoth, MD, PhD, ${ }^{\mathrm{a}}$ Lars Algotsson, $\mathrm{MD}, \mathrm{PhD},{ }^{\mathrm{a}} \mathrm{Björn} \mathrm{Brondén,} \mathrm{MD}, \mathrm{PhD},{ }^{\mathrm{a}}$ and \\ Henrik Bjursten, MD, $\mathrm{PhD}^{\mathrm{b}}$
}

\begin{abstract}
Objective: This study relates long-term mortality after cardiac surgery to different methods of measuring postoperative renal function, classified according to the Risk, Injury, Failure, Loss, and End-stage (RIFLE) criteria. The dynamics of acute kidney injury during hospital stay were studied by comparing renal function preoperatively, at its poorest measurement, and at discharge.
\end{abstract}

\begin{abstract}
Methods: A total of 5746 patients undergoing coronary artery bypass grafting were studied in a Cox analysis, over a median follow-up time of 6.0 years (range, 2.5-9.5 years). Renal function was determined using the highest and discharge levels of plasma creatinine by Cockroft-Gault and Modification of Diet in Renal Disease formulae. Acute kidney injury was classified according to the RIFLE criteria. Renal recovery was studied in a 2-dimensional matrix, and the impact of renal function at different time points was related to survival.
\end{abstract}

Results: Although the p-creatinine classified most patients in the nonacute kidney injury and Risk class; the Cockroft-Gault and Modification of Diet in Renal Disease formulae classified more patients in Injury and Failure classes; and higher Risk, Injury, and Failure classes were associated with increased long-term mortality. The effect of renal recovery on long-term survival was only in part associated with improved outcome. In addition, the poorest renal function was a stronger predictor of mortality compared with preoperative and discharge levels.

Conclusions: Classification using RIFLE criteria seems to be useful because it detects patients with renal impairment that affects long-term survival. The Modification of Diet in Renal Disease method seems to be the most robust method when predicting outcome, and the poorest renal function was the best predictor of outcome. Renal recovery was generally associated with better outcome. (J Thorac Cardiovasc Surg 2014;147:800-7)

Acute kidney injury (AKI) is common after cardiac surgery, and incidences between $7 \%$ and $40 \%$ have been reported depending on the definition used. ${ }^{1-4}$ AKI has welldocumented negative effects on postoperative morbidity and mortality, ${ }^{5}$ as well as the length of postoperative hospital stay and costs. ${ }^{6}$ In clinical practice, it is not obvious how this powerful predictor should be handled in a useful way.

First, almost all centers use the p-creatinine concentration for estimating glomerular renal filtration (GFR), and the shortcomings of this marker are well known. ${ }^{7}$ To compensate for this, different formulae have been constructed where other physiologic variables are introduced. The CockroftGault (CG) and the Modification of Diet in Renal Disease

From the Department of Anesthesia and Intensive Care ${ }^{\mathrm{a}}$ and Department of Cardiothoracic Surgery, ${ }^{\mathrm{b}}$ Clinical Sciences, Lund University, Lund, Sweden.

Disclosures: L.A. lectures for Orion Pharma AB and Abbott Scandinavia AB. H.B. has a vested interest in ErySave AB. All other authors have nothing to disclose with regard to commercial support.

Received for publication March 7, 2013; revisions received June 11, 2013; accepted for publication July 30, 2013; available ahead of print Oct 7, 2013.

Address for reprints: Alain Dardashti, MD, Department of Anesthesia and Intensive Care, Institute of Clinical Sciences, Faculty of Medicine Lund University, Skane University Hospital, SE-221 85 Lund, Sweden (E-mail: alain.dardashti@med.lu.se). 0022-5223/\$36.00

Copyright (c) 2014 by The American Association for Thoracic Surgery

http://dx.doi.org/10.1016/j.jtcvs.2013.07.073
(MDRD) formulae are 2 commonly used examples. The first expresses renal function as estimated creatinine clearance $(\mathrm{eCrCl})$ and the latter as estimated glomerular filtration rate (eGFR). The MDRD formula has been widely used in studies in cardiac surgery. ${ }^{8-14} \mathrm{P}$-creatinine, $\mathrm{eCrCl}$, and eGFR are still only estimates of true GFR.

A second challenge is that during and after cardiac surgery, renal function varies on a daily basis. ${ }^{15,16}$ Several authors have highlighted the observation that decreased renal function after cardiac surgery affects both short- and long-term mortality. ${ }^{10,11,17-20}$ The majority of these studies have mainly focused on the poorest renal function. However, some patients with AKI recover completely during their hospital stay, whereas others show no recovery at all. Earlier studies demonstrate conflicting results on renal recovery and long-term outcome. Therefore, there is a need for more studies on the dynamics of renal function after cardiac surgery.

The aim of this study was 2 -fold. The primary objective was to assess the importance of time point for measuring, and consequently the dynamics of renal recovery in relation to long-term mortality. The secondary aim was to compare 3 different plasma creatinine-based assessments of renal function (ie, absolute p-creatinine concentrations, $\mathrm{eCrCl}$ using the CG formula, and eGFR according to the MDRD formula) 

Abbreviations and Acronyms
AKI = acute kidney injury
$\mathrm{CABG}=$ coronary artery bypass grafting
$\mathrm{CG}=$ Cockroft-Gault
$\mathrm{CI}=$ confidence interval
$\mathrm{eCrCl}=$ estimated creatinine clearance
eGFR = estimated glomerular filtration rate
$\mathrm{GFR}=$ glomerular filtration rate
$\mathrm{HR}=$ hazard ratio
IABP $=$ intra-aortic balloon pump
MDRD $=$ Modification of Diet in Renal Disease
RIFLE $=$ Risk, Injury, Failure, Loss, and End-stage

using the Risk, Injury, Failure, Loss, and End-stage (RIFLE) criteria to find the best method for renal assessment.

\section{MATERIALS AND METHODS Study Design}

The study was approved by the local ethics committee. All patients who had undergone cardiac surgery at the Department of Cardiothoracic Surgery at the University Hospital in Lund, Sweden, between January 1, 2002, and December 31, 2008, were included.

\section{Database Management}

Data were mainly collected from the hospital's quality-control database, in which information is continuously collected on perioperative care during patients' hospital stays. Other sources of data were the blood bank and clinical chemistry databases at the hospital. Survival or time of death for each patient was determined from the national tax registry in May 2011, defining the follow-up period from 2.5 to 9.5 years. Where data were missing or extreme outliers were identified, patient records were read to complete the database. In cases of data mismatch between different data sources, the data were manually checked by consulting the patient's records.

After completing missing data from patient records, preoperative p-creatinine values were still missing in 104 patients. For these patients, the preoperative p-creatinine level was estimated using an imputation technique based on the p-creatinine level 1 day after surgery. The formula used was creatinine day $0=15.0+(0.86 \times$ creatinine day 1$)$, calculated by applying regression analysis to the relation between the preoperative p-creatinine level (on day 0 ) and the p-creatinine 1 day after surgery (day 1). ${ }^{21,22}$

\section{Patient Inclusion and Exclusion}

All patients who had undergone coronary artery bypass grafting (CABG) as the sole surgical intervention between January 1, 2002, and December 31, 2008, were included. The following predetermined exclusion criteria were used: emergency operation (defined as operation within 1 hour of the decision to operate) $(\mathrm{n}=125,2.1 \%)$, preoperative eGFR $($ MDRD) $<15 \mathrm{~mL} / \mathrm{min}(\mathrm{n}=20,0.3 \%)$, and death within 7 days of operation ( $\mathrm{n}=51,0.9 \%$ ) because we aimed to study long-term outcomes, and patients who die early most often have major cerebral or cardiac insult and seldom die of AKI due to available renal replacement therapies. Of a total of 5943 patients, 5746 constituted the study group after application of the exclusion criteria.

\section{Measurements of Renal Function}

Kidney function was based on p-creatinine levels, the absolute p-creatinine value, eGFR, ${ }^{9}$ or the eCrCl. ${ }^{23}$ Changes in p-creatinine, eGFR, and
eCrCl during the hospital stay were compared with the preoperative values (baseline value) to assess changes in kidney function. The commonly used MDRD formula used is as follows:

eGFR mL/min $/ 1.73 \mathrm{~m}^{2}=32,788 \times$ p-creatinine $\mathrm{e}^{-1.154} \times \mathrm{age}^{-0.203} \times$ [1.210 if black $] \times\left[0.742\right.$ if female.$^{9,24}$

In our population, the number of black patients is less than $1 \%$ and not recorded in journals. Therefore, we used the original formula with only that adjustment: $\mathrm{eGFR}=32,788 \times$ p-creatinine $\mathrm{e}^{-1.154} \times \mathrm{age}^{-0.203} \times[0.742$ if female]. The CG formula used was as follows:

$\mathrm{eCrCl}$ (female) $\mathrm{mL} / \mathrm{min}=([140$-age $] \times$ weight in $\mathrm{kg} \times 1.04) /(\mathrm{p}$-creatinine in $\mu \mathrm{mol} / \mathrm{L})$ or eCrCl $($ male $) \mathrm{mL} / \mathrm{min}=([140$-age $] \times$ weight in $\mathrm{kg} \times 1.23) /(\mathrm{p} \text {-creatinine in } \mu \mathrm{mol} / \mathrm{L})^{23}$

eGFR and $\mathrm{eCrCl}$ values calculated on the highest concentration of postoperative p-creatinine ( $\mathrm{p}$-creatinine peak ) are denoted as $\mathrm{eGFR}_{\text {peak }}$ and $\mathrm{eCrCl}$ peak, respectively. In line with this, eGFR and $\mathrm{eCrCl}$ values calculated on the level of p-creatinine closest to the day of discharge from hospital (p-creatinine discharge $_{\text {en }}$ are denoted as $\mathrm{eGFR}_{\text {discharge }}$ and $\mathrm{eCrCl}_{\text {discharge }}$, respectively.

We assumed that the "peak" values corresponded to the poorest kidney function and "discharge" values to the level of kidney function at the time of discharge from hospital. All p-creatinine concentrations were determined with the enzymatic colorimetric method ${ }^{25}$ with a $1.4 \%$ to $1.7 \%$ coefficient of variance. The reference method for determination of the calibrator used was isotope dilution/mass spectrometry.

\section{Definition of Acute Kidney Injury}

AKI was classified using the RIFLE scale. ${ }^{26}$ The RIFLE staging was made according to changes in levels of kidney function measured by p-creatinine, eGFR, and $\mathrm{eCrCl}$ (Table 1). Urinary output data were not available, so we used only the p-creatinine-based RIFLE classifications.

\section{Statistics}

The Student $t$ test was used for group comparisons. Unless otherwise stated, values are presented as the mean \pm 1 standard deviation. Unadjusted Kaplan-Meier curves were used to show differences in survival between groups. The Cox proportional hazard model was used to determine which factors had an adverse outcome on long-term survival in all survival analysis. Wald statistics were used to determine the strength of a relation. The increased risk for mortality during the study period expressed as adjusted hazard ratio (HR) obtained from the multivariate Cox proportional hazard model was used to compare relative risks between groups. On the basis of previous studies on the subject, the following variables were entered into the Cox analysis ${ }^{8,27-29}$ : history of cerebrovascular disease, diabetes, or chronic obstructive pulmonary disease; female gender; peripheral vascular disease; left ventricular ejection fraction $30 \%$ to $50 \%$; left ventricular ejection fraction less than $30 \%$; age; intra-aortic balloon pump (IABP) before surgery; IABP after surgery; previous percutaneous coronary intervention; postoperative myocardial infarction; postoperative sepsis; postoperative stroke; reoperation due to bleeding; postoperative mediastinitis or postoperative atrial fibrillation; body mass index; time on ventilator; and transfusion of red blood cells, plasma, and platelets. In addition to these risk factors, measures of renal function were entered depending on which RIFLE group of patients was being analyzed and which method was used for determining RIFLE group. HRs were estimated using patients classified as non-AKI as a reference for each method used for defining AKI respectively.

Statistical analysis was performed with Statistica software version 9.0 (StatSoft, Inc, Tulsa, Okla) for most of the analyses. The R-project (version 1.13.0) software with the survival package was used to test the proportional hazard assumption for a Cox regression model fit.

To study the effect of renal recovery, a 2-dimensional matrix was created in which 1 dimension was RIFLE $E_{\text {peak }}$ and the other was RIFLE $_{\text {discharge, }}$, based on MDRD eGFR. 
TABLE 1. Classification of acute kidney injury using the RIFLE classification system

\begin{tabular}{|c|c|c|c|c|}
\hline & Non-AKI & Risk & Injury & Failure \\
\hline Creatinine & $<50 \%$ creatinine increase & $50 \%-100 \%$ creatinine increase & $100 \%-150 \%$ creatinine increase & $\begin{array}{c}>150 \% \text { creatinine increase or } \\
\text { p-creatinine }>350 \mu \mathrm{mol} / \mathrm{L}\end{array}$ \\
\hline MDRD eGFR & $<25 \%$ eGFR decrease & $25 \%-50 \%$ eGFR decrease & $50 \%-75 \%$ eGFR decrease & $\begin{array}{l}>75 \% \text { eGFR decrease or } \\
\text { preoperative p-creatinine } \\
\quad>350 \mu \mathrm{mol} / \mathrm{L}\end{array}$ \\
\hline $\mathrm{CG}$ eCrCl & $<25 \%$ eCrCl decrease & $25 \%-50 \%$ eCrCl decrease & $50 \%-75 \%$ eCrCl decrease & $\begin{array}{l}>75 \% \text { eCrCl decrease or } \\
\text { preoperative p-creatinine } \\
\quad>350 \mu \mathrm{mol} / \mathrm{L}\end{array}$ \\
\hline
\end{tabular}

$\overline{A K I}$, Acute kidney injury; $C G$, Cockroft-Gault; $e C r C l$, estimated creatinine clearance; $e G F R$, estimated glomerular filtration rate; $M D R D$, Modification of Diet in Renal Disease; RIFLE, Risk, Injury, Failure, Loss, and End-stage.

To evaluate the relative strength in predicting outcome for renal function at different time points (before surgery, poorest renal function, and discharge), we performed a multivariate Cox survival analysis where eGFR represented preoperative levels; poorest renal function and discharge were entered as continuous variables in our model.

\section{RESULTS}

A total of 5746 patients were analyzed over a median follow-up time of 6.0 years (range, 2.5-9.5 years). The general characteristics and outcome of the cohort are presented in Table 2. The incidence of postoperative AKI (RIFLE classes $\mathrm{R}, \mathrm{I}$, and $\mathrm{F}$ ) varied depending on the method used to determine renal function. The number of patients classified as non-AKI differed depending on the time point (ie, peak or discharge) and method of measuring renal function (ie, p-creatinine, eCrCl, or eGFR). The lowest number was found using eGFR, and the highest number was found using p-creatinine as presented in Tables 3 and 4 .

\section{RIFLE Classification Based on Poorest Renal Function}

By comparing the 3 methods of renal function measuring, the $\mathrm{eGFR}_{\text {peak }}$ method yielded the highest number of patients with AKI, whereas the lowest number of patients classified with AKI was found in the p-creatinine peak $_{\text {group. The risk }}$ of mortality during the study period, expressed as HR, increased significantly in all RIFLE classes compared with non-AKI for all 3 expressions of renal function (Table 3 and Figure 1). The HR increased with more severe RIFLE class (ie, HR for RIFLE class $\mathrm{F}>\mathrm{I}>\mathrm{R}>$ non-AKI), with $\mathrm{GGFR}_{\text {peak }} \mathrm{F}$ as the only exception. Using the eGFR $\mathrm{Feak}$ and $\mathrm{eCrCl}$ peak led to more patients being classified as RIFLE classes R, I, and F than when p-creatinine peak $_{\text {was }}$ used.

\section{RIFLE Classification Based on Renal Function at Discharge}

More patients were classified in RIFLE classes R, I, and F when using $\mathrm{eCrCl}_{\text {discharge }}$ or eGFR $\mathrm{Gischarge}_{\text {e }}$ than when using p-creatinine discharge. $_{\text {In addition, }}$ GFR $_{\text {discharge }}$ led to more patients being classified as $\mathrm{AKI}$ than $\mathrm{eCrCl}$ and p-creatinine (Table 4). HR increased progressively with more serious
RIFLE class only in the eGFR discharge $_{\text {measures. Classifica- }}$ tion using $\mathrm{p}$-creatinine discharge $_{\text {and }} \mathrm{eCrCl}_{\text {discharge }}$ showed a progressive increase in HR compared with non-AKI in RIFLE classes R and I, but the value of HR decreased in RIFLE class $F$. With p-creatinine discharge $_{\text {RIFLE class } F \text { as }}$ the only exception, all HRs in RIFLE classes R, I, and F for all 3 methods were significantly higher compared with non-AKI, respectively.

\section{Dynamics of Renal Recovery and Its Impact on Survival}

A 2-dimensional matrix in which 1 dimension was RI-

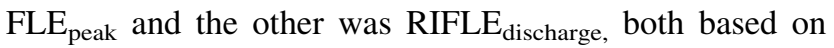
eGFR, was constructed to demonstrate the effect of recovery (Table 5). The HR for long-term mortality for all postoperative AKI (RIFLE classes R, I, and F) with or without recovery was 1.56 (confidence interval [CI], 1.371.77; $P<.001$ ). The HR for patients with any degree of AKI who showed complete recovery to non-AKI was 1.42 (CI, 1.21-1.66; $P<.001)$. The HR for patients with any degree of remaining AKI at discharge was 1.69 (CI, 1.44-1.99; $P<.001)$. Long-term mortality HR for patients who recovered to non-AKI at discharge was not increased if $\mathrm{eGFR}_{\text {peak }}$ had been RIFLE R. However, if eGFR peak $_{\text {classified the }}$ patients as RIFLE I or F, it resulted in an increased HR,

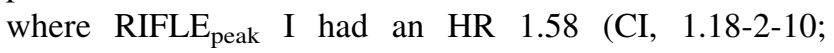
$P=.002)$, and those classified as RIFLE peak $\mathrm{F}$ had an HR 2.53 (CI, 1.84-3.48; $P<.001$ ).

\section{Relative Importance of Renal Function at Different Time Points}

In a separate survival analysis where the 3 values of

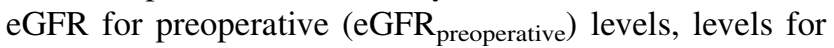
poorest renal function $\left(\mathrm{eGFR}_{\text {peak }}\right)$, and levels at discharge $\left(\mathrm{eGFR}_{\text {discharge }}\right)$ were entered separately, the eGFR peak $_{\text {levels }}$ contributed the most to the model and were thus the most predictive for outcome. The HR for $\mathrm{eGFR}_{\text {preoperative was }}$ $0.99(P<.0001$; Wald $=32.91)$, the HR for eGFR discharge was $0.98(P<.0001$; Wald $=44.98)$, and the HR for $\mathrm{eGFR}_{\text {peak }}$ was $0.98(P<.0001$; Wald $=80.16)$. 
TABLE 2. Preoperative characteristics and outcomes of the entire study cohort presented as mean (standard deviation) for continuous variables or number (percent) for dichotomous variables

\begin{tabular}{|c|c|c|}
\hline Characteristic & No. & $\begin{array}{c}\text { Mean (SD) or } \\
\text { n (\%) } \\
\end{array}$ \\
\hline Age & 5742 & $67.3( \pm 9.7)$ \\
\hline Female gender & 5742 & $1293(22.5)$ \\
\hline Body mass index & 5735 & $27.1( \pm 4)$ \\
\hline Diabetes & 5742 & $1270(2)$ \\
\hline History of cerebrovascular injury & 5742 & $520(9)$ \\
\hline Previous vascular surgery & 5742 & $520(9)$ \\
\hline COPD & 5742 & $529(9.2)$ \\
\hline Peripheral vascular disease & 5742 & $821(14)$ \\
\hline Previous myocardial infarction & 5742 & 2567 (44.7) \\
\hline LVEF 30\%-50\% & 5742 & $1589(27.7)$ \\
\hline LVEF <30\% & 5742 & $371(6.5)$ \\
\hline IABP before surgery & 5742 & $170(3)$ \\
\hline Previous CABG & 5742 & $120(2.1)$ \\
\hline Previous PCI & 5742 & $684(11.9)$ \\
\hline EuroSCORE, additive & 5742 & $4.8(3.3)$ \\
\hline \multicolumn{3}{|l|}{ NYHA class } \\
\hline I & 5742 & $1375(24)$ \\
\hline II & 5742 & $1900(33.1)$ \\
\hline III & 5742 & $1781(31)$ \\
\hline IV & 5742 & $685(11.9)$ \\
\hline \multicolumn{3}{|l|}{ CCS class } \\
\hline I & 5742 & $214(3.7)$ \\
\hline II & 5742 & $1892(33.0)$ \\
\hline III & 5742 & $2464(42.9)$ \\
\hline IV & 5742 & $1167(20.3)$ \\
\hline \multicolumn{3}{|l|}{ Outcome } \\
\hline Use of CBP & 5742 & $5521(96.2)$ \\
\hline Perfusion time (min) & 5521 & $80.7( \pm 26.5)$ \\
\hline Crossclamp time (min) & 5521 & $47.9( \pm 17.2)$ \\
\hline IABP after surgery & 5742 & $161(2.8)$ \\
\hline Hours in the ICU & 5627 & $22(19-26)$ \\
\hline Need of RRT postoperative & 5633 & $20(0,4)$ \\
\hline Heart failure & 5049 & $231(4.6)$ \\
\hline Postoperative myocardial infarction & 5049 & $96(1.9)$ \\
\hline Postoperative sepsis & 5049 & $62(1.1)$ \\
\hline Postoperative permanent stroke & 5049 & $35(0.8)$ \\
\hline Postoperative atrial fibrillation & 5049 & $1294(25.6)$ \\
\hline Reoperated for bleeding & 5740 & $279(4.9)$ \\
\hline Reoperated for mediastinitis & 5740 & $79(1.4)$ \\
\hline Hemoglobin, preoperative $(\mathrm{g} / \mathrm{L})$ & 5616 & $132.4( \pm 15.8)$ \\
\hline Hemoglobin at discharge $(\mathrm{g} / \mathrm{L})$ & 5672 & $103.4( \pm 11.4)$ \\
\hline Erythrocytes transfused & 5742 & $3105(54)$ \\
\hline Plasma transfused & 5742 & $1984(34.5)$ \\
\hline Platelets transfused & 5742 & $694(12.1)$ \\
\hline P-creatinine, preoperative $(\mu \mathrm{mol} / \mathrm{L})$ & 5347 & $86.5( \pm 29.4)$ \\
\hline $\begin{array}{l}\text { P-creatinine, preoperative including } \\
\text { estimates }(\mu \mathrm{mol} / \mathrm{L})\end{array}$ & 5742 & $86.4( \pm 29.3)$ \\
\hline P-creatinine, peak $(\mu \mathrm{mol} / \mathrm{L})$ & 5742 & $103.8( \pm 51)$ \\
\hline P-creatinine at discharge $(\mu \mathrm{mol} / \mathrm{L})$ & 5742 & $90.2( \pm 40.6)$ \\
\hline MDRD eGFR, preoperative $\mathrm{mL} / \mathrm{min} / 1.73 \mathrm{~m}^{2}$ & 5742 & $83.7( \pm 23.8)$ \\
\hline MDRD eGFR, peak $\mathrm{mL} / \mathrm{min} / 1.73 \mathrm{~m}^{2}$ & 5742 & $72.7( \pm 25.8)$ \\
\hline MDRD eGFR discharge $\mathrm{mL} / \mathrm{min} / 1.73 \mathrm{~m}^{2}$ & 5742 & $82.8( \pm 27.1)$ \\
\hline
\end{tabular}

TABLE 2. Continued

\begin{tabular}{|c|c|c|}
\hline Characteristic & No. & $\begin{array}{c}\text { Mean (SD) or } \\
\text { n (\%) } \\
\end{array}$ \\
\hline $\mathrm{CG}$ eCrCl, preoperative $\mathrm{mL} / \mathrm{min}$ & 5741 & $88.0( \pm 32.9)$ \\
\hline $\mathrm{CG}$ eCrCl, peak mL/min & 5741 & $77.9( \pm 33.0)$ \\
\hline $\mathrm{CG} \mathrm{eCrCl}$ at discharge $\mathrm{mL} / \mathrm{min}$ & 5742 & $87.1( \pm 34.9)$ \\
\hline \multicolumn{3}{|c|}{$\begin{array}{l}C A B G \text {, Coronary artery bypass grafting; } C B P \text {, cardiopulmonary bypass; } C C S \text {, Cana- } \\
\text { dian Cardiovascular Society; } C G \text {, Cockroft-Gault formula; } C O P D \text {, chronic obstruc- } \\
\text { tive pulmonary disease; } e C r C l \text {, estimated creatinine clearance; } e G F R \text {, estimated } \\
\text { glomerular filtration fate; EuroSCORE, European System for Cardiac Operative } \\
\text { Risk Evaluation; IABP, intra-aortic balloon pump; } I C U \text {, intensive care unit; } L V E F \text {, } \\
\text { left ventricular ejection fraction; } M D R D \text {, Modification of Diet in Renal Disease; } \\
N Y H A \text {, New York Heart Association; } P C I \text {, percutaneous coronary intervention; } \\
R R T \text {, renal replacement therapy; } S D \text {, standard deviation. }\end{array}$} \\
\hline
\end{tabular}

To further clarify which time for renal measurement is the most important, all 3 variables (eGFR preoperative, $_{\text {eGFR }}$ discharge, and eGFR ${ }_{\text {peak }}$ ) were forced in a separate Cox analysis, and only the $\mathrm{eGFR}_{\text {peak }}$ values remained significant with an $\mathrm{HR}$ of 0.98 $(P<.0001$; Wald $=41.4)$. The values for $\mathrm{eGFR}_{\text {discharge }}$ changed to an HR of $1.0(P=.3$; Wald $=1.1)$, and the values for preoperative eGFR changed to an HR of $1.0(P=.6$; Wald $=0.25$ ).

\section{DISCUSSION}

In this large single-center cohort of patients with no history of chronic kidney failure undergoing CABG, we aimed at assessing different methods of evaluating postoperative AKI with the RIFLE system and correlating them to longterm mortality. The eGFR peak value was a stronger predictor of death than the eGFR $\mathrm{Preoperative}$ or eGFR $\mathrm{Gischarge}_{\text {. The high- }}$ est number of patients was classified as AKI with the eGFR method. Patients with a recovered renal function at discharge had a normalized HR if their AKI was classified as RIFLE R, but the remaining had an increased mortality risk if they had recovered from RIFLE I or F.

Both time points for measuring and the dynamics of renal recovery seem important because the poorest renal function appears vastly superior in predicting survival. An analysis was performed in which eGFR from 3 different time points (preoperative, peak, and discharge) were entered separately into the Cox regression model, followed by another analysis in which all eGFR measures were entered at the same time. The results were the same in both analyses, where eGFR peak was indisputably the strongest predictor (HR, 0.98; $P<.0001$; Wald $=41.4$ ). This corresponds to a risk increase of $2 \%$ for every milliliter/minute decrease in eGFR peak. To our knowledge, this has not been reported before. In the RIFLE classification presented in Tables 3 and 4, we see that peak levels rather than discharge levels detect more patients in higher-risk classes (I and F). Moreover, patients at the lower $\mathrm{R}$ risk class had a lower HR. Therefore, our RIFLE analysis confirms the strength of peak levels.

The results of the survival analysis based on the renal function estimated from the highest postoperative level of 
TABLE 3. Relative risk of mortality (expressed as adjusted hazard ratio) after coronary artery bypass grafting depending on RIFLE class at poorest measured renal function (RIFLE $E_{\text {peak }}$ ) during hospital stay

\begin{tabular}{|c|c|c|c|c|c|}
\hline & & Non-AKI & $\mathbf{R}$ & I & $\mathbf{F}$ \\
\hline 1 & P-creatinine $\mathrm{n}=5742$ & $5092(88.7 \%)$ & $\begin{array}{l}1.57(1.31-1.89) \\
P<.000001 \\
463(8.1 \%)\end{array}$ & $\begin{array}{l}1.62(1.13-2.33) \\
P=.009435 \\
103(1.8 \%)\end{array}$ & $\begin{array}{l}1.90(1.32-2.74) \\
P=.000600 \\
84(1.5 \%)\end{array}$ \\
\hline 2 & $\mathrm{CG}$ eCrCl $\mathrm{n}=5735$ & $4147(72.3 \%)$ & $\begin{array}{l}1.32(1.13-1.56) \\
P=.000716 \\
942(16.4 \%)\end{array}$ & $\begin{array}{l}1.53(1.23-1.90) \\
P=.000145 \\
327(5.7 \%)\end{array}$ & $\begin{array}{l}2.03(2.03-2.53) \\
P<.000001 \\
319(5.6 \%)\end{array}$ \\
\hline 3 & MDRD eGFR $\mathrm{n}=5742$ & $3855(67.1 \%)$ & $\begin{array}{l}1.29(1.09-1.51) \\
P=.002536 \\
1051(18.3 \%)\end{array}$ & $\begin{array}{l}1.85(1.51-2.27) \\
P<.000001 \\
400(7.0 \%)\end{array}$ & $\begin{array}{l}1.85(1.85-2.26) \\
P<.000001 \\
436(7.6 \%)\end{array}$ \\
\hline
\end{tabular}

The 3 methods used to measure renal function were p-creatinine, the CG formula for creatinine clearance, and MDRD formulae. $P$ values refer to comparison with non-AKI. $A K I$, Acute kidney injury; $C G$, Cockroft-Gault formula; $M D R D$, Modification of Diet in Renal Disease; $e C r C l$, estimated creatinine clearance; $e G F R$, estimated glomerular filtration fate; RIFLE, Risk, Injury, Failure, Loss, and End-stage.

p-creatinine ( $\mathrm{p}$-creatinine $\mathrm{peak}$ ) were similar to those reported in previous studies, ${ }^{10,11,17}$ where increasing renal dysfunction/RIFLE class resulted in increasing risk of long-term mortality. Hobson and colleagues, ${ }^{10}$ also using p-creatinine peak , showed increasing HRs with higher RIFLE classes. Thus, our data seem to confirm the results of previous studies. We also studied the predictive value of renal function measures at discharge from hospital for longterm survival. Our data indicated poorer survival with increasing degree of renal dysfunction, where the MDRD formulae predicted increasing risks of more serious RIFLE classes, whereas the p-creatinine value did not predict an increase in HR for every RIFLE class (Table 4). On the other

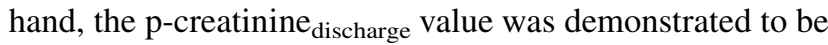
of statistically lower strength in predicting death, so the clinical value of the p-creatinine discharge $_{\text {estimates is there- }}$ fore limited. Our findings are in concordance with previous studies, in which an association between renal function and long-term mortality has been shown. ${ }^{19,30}$ It has also been shown that the magnitude and duration of post-cardiac surgery AKI is proportional to long-term mortality. ${ }^{1,10,11,31}$

The use of eGFR and eCrCl in conjunction with AKI has been questioned, and caution for the use of these estimates in the context of AKI has been advocated ${ }^{32-34}$ given that these estimations have been developed for patients with chronic kidney disease and a p-creatinine in steady state, which is not the case in an AKI scenario. However, these estimates have been used in conjunction with post cardiac surgery AKI. ${ }^{8,10,28}$ A higher sensitivity for RIFLE classes Risk and Injury in cardiac surgery also has been suggested using eGFR compared with p-creatinine. ${ }^{33}$ A similar finding was made in the present study where the

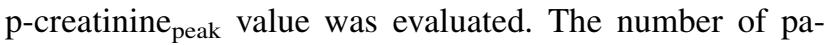
tients classified as AKI was higher in the eGFR group than in the p-creatinine and $\mathrm{eCrCl}$ groups. Another important piece of the puzzle was findings in a recent study from our group, ${ }^{16}$ in which different estimates of renal function versus iohexol clearance in cardiac surgery were

TABLE 4. Relative risk of mortality (expressed as hazard ratio) during follow-up depending on RIFLE class at discharge (RIFLE discharge $_{\text {) }}$

\begin{tabular}{|c|c|c|c|c|c|}
\hline & & Non-AKI & $\mathbf{R}$ & $\mathbf{I}$ & $\mathbf{F}$ \\
\hline 1 & P-creatinine $\mathrm{n}=5742$ & $5579(97.2 \%)$ & $\begin{array}{l}1.90(1.39-2.87) \\
P=.000050 \\
123(2.1 \%)\end{array}$ & $\begin{array}{l}2.07(1.09-3.92) \\
P=.025779 \\
24(0.4 \%)\end{array}$ & $\begin{array}{l}1.15(0.57-2.33) \\
P=.693115 \\
16(0.3 \%)\end{array}$ \\
\hline 2 & $\mathrm{CG} \mathrm{eCrCl} \mathrm{n}=5735$ & $5116(89.2 \%)$ & $\begin{array}{l}1.37(1.13-1.67) \\
P=.001363 \\
442(7.7 \%)\end{array}$ & $\begin{array}{l}2.00(1.40-2.86) \\
P=.000160 \\
89(1.6 \%)\end{array}$ & $\begin{array}{l}1.60(1.12-2.28) \\
P=.010398 \\
88(1.5 \%)\end{array}$ \\
\hline 3 & MDRD eGFR $\mathrm{n}=5742$ & $4920(85.7 \%)$ & $\begin{array}{l}1.45(1.21-1.74) \\
P=.000045 \\
561(9.8 \%)\end{array}$ & $\begin{array}{l}1.75(1.30-2.37) \\
P=.000275 \\
143(2.5 \%)\end{array}$ & $\begin{array}{l}1.94(1.43-2.63) \\
P=.000018 \\
118(2.0 \%)\end{array}$ \\
\hline
\end{tabular}

The 3 methods used to measure renal function were p-creatinine, the CG formula for creatinine clearance, and MDRD eGFR. AKI, Acute kidney injury; $C G$, Cockroft-Gault formula; $e C r C l$, estimated creatinine clearance; $e G F R$, estimated glomerular filtration fate; $M D R D$, Modification of Diet in Renal Disease; RIFLE, Risk, Injury, Failure, Loss, and End-stage. 


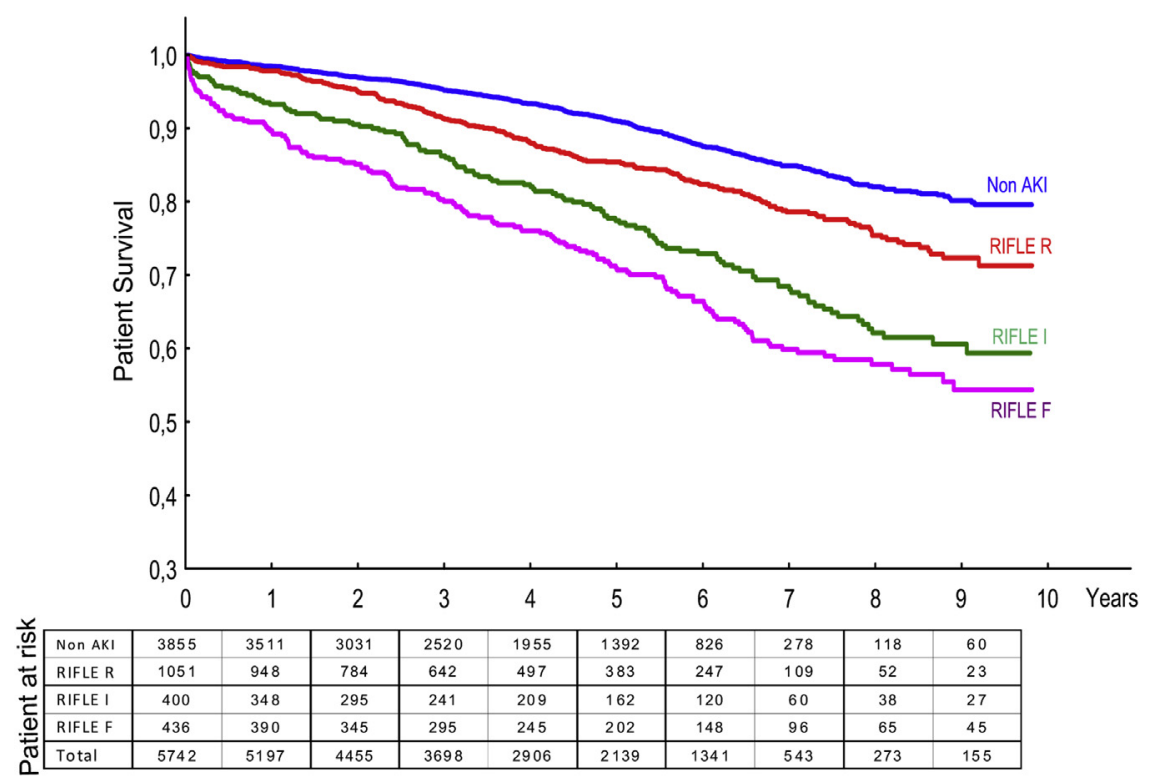

FIGURE 1. Unadjusted Kaplan-Meier plot depicting the survival of patients depending on level of AKI stratified by the RIFLE classification based on MDRD eGFR $_{\text {peak }}$ calculations. AKI, Acute kidney injury; RIFLE, Risk, Injury, Failure, Loss, and End-stage.

evaluated. We found that MDRD eGFR was better than CG $\mathrm{eCrCl}$ in estimating clearance in postoperative patients. ${ }^{16}$ MDRD eGFR seems to be a robust biomarker for GFR in patients undergoing cardiac surgery under non-steadystate conditions. In addition, this study supports that both $\mathrm{eCrCl}$ and eGFR were superior to crude p-creatinine in identifying patients with AKI after CABG surgery, and eGFR was slightly superior to eCrCl.

The poorest renal function postoperatively and the renal function at discharge from hospital can be combined to assess the impact of these changes in renal function on survival. RIFLE classes based on MDRD eGFR were used to create a 2-dimensional matrix with peak and discharge RIFLE class. MDRD eGFR was used because this method reflected renal function better than $\mathrm{eCrCl}$ and p-creatinine, as discussed earlier. When analyzing the effect of total recovery from any degree of AKI to non-AKI at discharge, the results were beneficial in terms of survival compared with patients without RIFLE R recovery. This is in accordance with previous studies. ${ }^{1,4,10,11,19,31}$ Of note, this was not true for the groups that had been in RIFLE groups I and $\mathrm{F}$ at the poorest level, with a remaining $\mathrm{HR}$ proportional to the worse degree of AKI. A similar result was presented by Mehta and colleagues, ${ }^{4}$ reporting a slightly increased long-term mortality in the group showing partial recovery from acute renal failure (HR 1.58 vs 1.42). Loef and colleagues ${ }^{19}$ reported an increase in long-term mortality in patients with AKI, irrespective of postoperative

TABLE 5. Relative risk of mortality (expressed as hazard ratio) during follow-up depending on the combination of RIFLE class at discharge (RIFLE $_{\text {discharge }}$ ) and poorest measured renal function (RIFLE peak $)$

\begin{tabular}{|c|c|c|c|c|}
\hline & Non-AKI peak & R peak & I peak & F peak \\
\hline Non-AKI at discharge & $3855(67.1 \%)$ & $\begin{array}{l}1.18(0.98-1.43) \\
P=.085694 \\
723(12.6 \%)\end{array}$ & $\begin{array}{l}1.58(1.18-2.10) \\
P=.001975 \\
204(3.6 \%)\end{array}$ & $\begin{array}{l}2.53(1.84-3.48) \\
P<.00001 \\
139(2.4 \%)\end{array}$ \\
\hline $\mathrm{R}$ at discharge & & $\begin{array}{l}1.49(1.16-1.91) \\
P=.001891 \\
328(5.7 \%)\end{array}$ & $\begin{array}{l}2.17(1.59-2.96) \\
P<.00001 \\
125(2.2 \%)\end{array}$ & $\begin{array}{l}1.19(0.80-1.76) \\
P=.382464 \\
107(1.9 \%)\end{array}$ \\
\hline I at discharge & & & $\begin{array}{l}1.95(1.27-3.00) \\
P=.002285 \\
71(1.2 \%)\end{array}$ & $\begin{array}{l}1.82(1.18-2.81) \\
P=.007228 \\
72(1.3 \%)\end{array}$ \\
\hline $\mathrm{F}$ at discharge & & & & $\begin{array}{l}2.07(1.50-2.85) \\
P=.000008 \\
118(2.1 \%)\end{array}$ \\
\hline
\end{tabular}

Renal function was measured by MDRD eGFR. AKI, Acute kidney injury; RIFLE, Risk, Injury, Failure, Loss, and End-stage. 
renal recovery. Although stratifying the patients into groups according to their RIFLE class provides more information about the effect of recovery, depending on the degree of $\mathrm{AKI}$ at peak p-creatinine level and the degree of recovery at discharge, the groups become smaller, thus increasing the uncertainty in the analysis. However, studying the 2-dimensional analysis, we can see that long-term mortality HR for all patients classified as non-AKI at discharge was directly proportional to the AKI level at RIFLE $E_{\text {peak }}$ for these patients.

One of the strengths of this study is the database, which contains information on many perioperative variables, such as laboratory results and transfusion data. In addition, many variables had a high completion rate, with more than 99\% complete data follow-up. Moreover, the present study includes only patients undergoing CABG, whereas several other studies have included a mixed population. ${ }^{31,35}$ The lack of baseline p-creatinine in using the RIFLE classification ${ }^{10}$ has been highlighted as a limitation. ${ }^{32}$ Preoperative p-creatinine levels were missing in only $1.8 \%$ of our subjects, and we used an imputation technique based on the p-creatinine level on the first postoperative day, which has a correlation estimate of $0.89 .{ }^{21}$ In a post hoc analysis, we checked the demographics for the patients who had their preoperative creatinine imputed. These patients had a slightly higher European System for Cardiac Operative Risk Evaluation (EuroSCORE) (5.6 vs 4.8) and a higher frequency of preoperative IABP ( $3 \%$ vs $11 \%$ ) but did not differ in any other characteristic. We did not take into account the time to recovery in our analysis, although this may be a factor influencing long-term survival, as reported by Brown and colleagues. ${ }^{1}$ Although the study comprises more than 5000 individuals, the numbers of patients in the more serious classes of renal dysfunction are relatively small, especially in the 2-dimensional matrix. This could lead to an overparameterization, which subsequently will lead to a risk of over- or underestimation of the HRs in these small groups. Other limitations are the single-center, retrospective study, the lack of data on urinary output, and the inherent weaknesses of the MDRD and CG formula, such as extreme body weight, low GFR, and age of the cohort. A more accurate measure of GFR would further strengthen the results of a study of this type. Today, p-creatinine is the most commonly used marker for renal function despite its shortcomings, but cystatin $\mathrm{C}$ has recently been suggested as a better marker. ${ }^{16}$

\section{CONCLUSIONS}

In concordance with previous studies, out study shows that renal function plays a pivotal role in long-term outcome in cardiac surgery. The dynamics of renal function during hospital stay also is an important factor, where recovery seems to be beneficial, and until better serum markers for renal function are found, eGFR based on the MDRD formula seems to yield the most reliable results. The present study also suggests that the poorest measured postoperative renal function is the most predictive for mortality.

The authors thank Peter Höglund for invaluable help with survival statistics, Jan Karlsson for developing and maintaining the primary database, and Max Bell at Karolinska Hospital in Stockholm for engaging discussions on the topic.

\section{References}

1. Brown JR, Kramer RS, Coca SG, Parikh CR. Duration of acute kidney injury impacts long-term survival after cardiac surgery. Ann Thorac Surg. 2010;90: 1142-8.

2. Rosner MH, Okusa MD. Acute kidney injury associated with cardiac surgery. Clin J Am Soc Nephrol. 2006;1:19-32.

3. Khilji SA, Khan AH. Acute renal failure after cardiopulmonary bypass surgery. $J$ Ayub Med Coll Abbottabad. 2004;16:25-8.

4. Mehta RH, Honeycutt E, Patel UD, Lopes RD, Shaw LK, Glower DD, et al. Impact of recovery of renal function on long-term mortality after coronary artery bypass grafting. Am J Cardiol. 2010;106:1728-34.

5. Mangano CM, Diamondstone LS, Ramsay JG, Aggarwal A, Herskowitz A, Mangano DT. Renal dysfunction after myocardial revascularization: risk factors, adverse outcomes, and hospital resource utilization. The Multicenter Study of Perioperative Ischemia Research Group. Ann Intern Med. 1998; 128:194-203.

6. Dasta JF, Kane-Gill SL, Durtschi AJ, Pathak DS, Kellum JA. Costs and outcomes of acute kidney injury (AKI) following cardiac surgery. Nephrol Dial Transplant. 2008;23:1970-4.

7. Coca SG, Yalavarthy R, Concato J, Parikh CR. Biomarkers for the diagnosis and risk stratification of acute kidney injury: a systematic review. Kidney Int. 2008; 73:1008-16.

8. Cooper WA, O'Brien SM, Thourani VH, Guyton RA, Bridges CR, Szczech LA, et al. Impact of renal dysfunction on outcomes of coronary artery bypass surgery: results from the Society of Thoracic Surgeons National Adult Cardiac Database. Circulation. 2006;113:1063-70.

9. Levey AS, Bosch JP, Lewis JB, Greene T, Rogers N, Roth D. A more accurate method to estimate glomerular filtration rate from serum creatinine: a new prediction equation. Modification of Diet in Renal Disease Study Group. Ann Intern Med. 1999;130:461-70.

10. Hobson CE, Yavas S, Segal MS, Schold JD, Tribble CG, Layon AJ, et al. Acute kidney injury is associated with increased long-term mortality after cardiothoracic surgery. Circulation. 2009;119:2444-53.

11. Brown JR, Cochran RP, MacKenzie TA, Furnary AP, Kunzelman KS, Ross CS, et al. Long-term survival after cardiac surgery is predicted by estimated glomerular filtration rate. Ann Thorac Surg. 2008;86:4-11.

12. Englberger L, Suri RM, Li Z, Casey ET, Daly RC, Dearani JA, et al. Clinical accuracy of RIFLE and Acute Kidney Injury Network (AKIN) criteria for acute kidney injury in patients undergoing cardiac surgery. Crit Care. 2011;15:R16.

13. Hillis GS, Croal BL, Buchan KG, EI-Shafei H, Gibson G, Jeffrey RR, et al. Renal function and outcome from coronary artery bypass grafting: impact on mortality after a 2.3-year follow-up. Circulation. 2006;113:1056-62.

14. Bagshaw SM, George C, Bellomo R. A comparison of the RIFLE and AKIN criteria for acute kidney injury in critically ill patients. Nephrol Dial Transplant. 2008;23:1569-74.

15. Del Duca D, Iqbal S, Rahme E, Goldberg P, de Varennes B. Renal failure after cardiac surgery: timing of cardiac catheterization and other perioperative risk factors. Ann Thorac Surg. 2007;84:1264-71.

16. Bronden B, Eyjolfsson A, Blomquist S, Dardashti A, Ederoth P, Bjursten H. Evaluation of cystatin $\mathrm{C}$ with iohexol clearance in cardiac surgery. Acta Anaesthesiol Scand. 2011;55:196-202.

17. Brown JR, Cochran RP, Dacey LJ, Ross CS, Kunzelman KS, Dunton RF, et al. Perioperative increases in serum creatinine are predictive of increased 90-day mortality after coronary artery bypass graft surgery. Circulation. 2006;114: I409-13.

18. Bove T, Calabro MG, Landoni G, Aletti G, Marino G, Crescenzi G, et al. The incidence and risk of acute renal failure after cardiac surgery. $J$ Cardiothorac Vasc Anesth. 2004;18:442-5. 
19. Loef BG, Epema AH, Smilde TD, Henning RH, Ebels T, Navis G, et al. Immediate postoperative renal function deterioration in cardiac surgical patients predicts in-hospital mortality and long-term survival. J Am Soc Nephrol. 2005;16: 195-200.

20. Lok CE, Austin PC, Wang H, Tu JV. Impact of renal insufficiency on short- and long-term outcomes after cardiac surgery. Am Heart J. 2004;148:430-8.

21. Dardashti A, Ederoth P, Algotsson L, Bronden B, Luhrs C, Bjursten H. Blood transfusion after cardiac surgery: is it the patient or the transfusion that carries the risk? Acta Anaesthesiol Scand. 2011;55:952-61.

22. Bo TH, Dysvik B, Jonassen I. LSimpute: accurate estimation of missing values in microarray data with least squares methods. Nucleic Acids Res. 2004;32:e34.

23. Cockcroft DW, Gault MH. Prediction of creatinine clearance from serum creatinine. Nephron. 1976;16:31-41.

24. K/DOQI clinical practice guidelines for chronic kidney disease: evaluation, classification, and stratification. Am J Kidney Dis. 2002;39:S1-266.

25. Fossati P, Prencipe L, Berti G. Enzymic creatinine assay: a new colorimetric method based on hydrogen peroxide measurement. Clin Chem. 1983;29:1494-6.

26. Bellomo R, Ronco C, Kellum JA, Mehta RL, Palevsky P. Acute renal failuredefinition, outcome measures, animal models, fluid therapy and information technology needs: the Second International Consensus Conference of the Acute Dialysis Quality Initiative (ADQI) Group. Crit Care. 2004;8:R204-12.

27. Wijeysundera DN, Rao V, Beattie WS, Ivanov J, Karkouti K. Evaluating surrogate measures of renal dysfunction after cardiac surgery. Anesth Analg. 2003; 96:1265-73.
28. Brown JR, Cochran RP, Leavitt BJ, Dacey LJ, Ross CS, MacKenzie TA, et al Multivariable prediction of renal insufficiency developing after cardiac surgery Circulation. 2007;116:I139-43.

29. Holzmann MJ, Hammar N, Ahnve S, Nordqvist T, Pehrsson K, Ivert T. Renal insufficiency and long-term mortality and incidence of myocardial infarction in patients undergoing coronary artery bypass grafting. Eur Heart J. 2007;28: 865-71.

30. Loef BG, Epema AH, Navis G, Ebels T, Stegeman CA. Postoperative renal dysfunction and preoperative left ventricular dysfunction predispose patients to increased long-term mortality after coronary artery bypass graft surgery. $\mathrm{Br} J$ Anaesth. 2009;102:749-55.

31. Bihorac A, Yavas S, Subbiah S, Hobson CE, Schold JD, Gabrielli A, et al. Longterm risk of mortality and acute kidney injury during hospitalization after major surgery. Ann Surg. 2009;249:851-8.

32. Cruz DN, Ricci Z, Ronco C. Clinical review: RIFLE and AKIN-time for reappraisal. Crit Care. 2009;13:211.

33. Englberger L, Suri RM, Schaff HV. RIFLE is not RIFLE: on the comparability of results. Crit Care. 2009;13:429.

34. Pickering JW, Endre ZH. GFR shot by RIFLE: errors in staging acute kidney injury. Lancet. 2009;373:1318-9.

35. Joannidis M, Metnitz B, Bauer P, Schusterschitz N, Moreno R, Druml W, et al. Acute kidney injury in critically ill patients classified by AKIN versus RIFLE using the SAPS 3 database. Intensive Care Med. 2009;35: 1692-702. 